\title{
Bornyl caffeate induces apoptosis in human breast cancer MCF-7 cells via the ROS- and JNK-mediated pathways
}

\author{
Chuan-bin YANG ${ }^{1}$, Wei-jing PEI ${ }^{2}$, Jia ZHAO ${ }^{1}$, Yuan-yuan $C H E N G^{1}$, Xiao-hui ZHENG ${ }^{2,3}$, Jian-hui RONG ${ }^{1, *}$ \\ ${ }^{1}$ School of Chinese Medicine, Li Ka Shing Faculty of Medicine, The University of Hong Kong, Pokfulam, Hong Kong, China; ${ }^{2}$ RITS and \\ NWU Joint Laboratory for New Drugs Research of TCM, Research Institute of Tsinghua University in Shenzhen, Shenzhen 518000, \\ China; ${ }^{3}$ Key Laboratory of Resource Biology and Biotechnology in Western China, School of Life Sciences, Northwest University, Xi'an \\ 710069, China
}

Aim: The purpose of the present study was to investigate the anticancer activity of bornyl caffeate in the human breast cancer cell line MCF-7.

Methods: The cell viability was determined using the MTT assay, and apoptosis was initially defined by monitoring the morphology of the cell nuclei and staining an early apoptotic biomarker with Annexin V-FITC. The mitochondrial membrane potential was visualized by JC-1 under fluorescence microscopy, whereas intracellular reactive oxygen species (ROS) were assessed by flow cytometry. The expression of apoptosis-associated proteins was determined by Western blotting analysis.

Results: Bornyl caffeate induced apoptosis in MCF-7 cells in a dose- and time-dependent manner. Consistently, bornyl caffeate increased Bax and decreased Bcl-xl, resulting in the disruption of MMP and subsequent activation of caspase-3. Moreover, bornyl caffeate triggered the formation of ROS and the activation of the mitogen-activated protein (MAP) kinases p38 and c-Jun N-terminal kinase (JNK). Antioxidants attenuated the activation of MAP kinase p38 but barely affected the activation of JNK. Importantly, the cytotoxicity of bornyl caffeate was partially attenuated by scavenging ROS and inhibited by MAP kinases and caspases.

Conclusion: The present study demonstrated that bornyl caffeate induced apoptosis in the cancer cell line MCF-7 via activating the ROS- and JNK-mediated pathways. Thus, bornyl caffeate may be a potential anticancer lead compound.

Keywords: cytotoxicity; apoptosis; human breast cancer MCF-7 cells; bornyl caffeate

Acta Pharmacologica Sinica advance online publication, XX XXX 2013; doi: 10.1038/aps.2013.162

\section{Introduction}

Alteration of the physiological apoptotic pathways and disruption of normal homeostasis are known to cause the initiation, progression and metastasis of different cancers ${ }^{[1,2]}$. Pharmacological induction of apoptosis in cancer cells has emerged as a key anticancer strategy over the past several decades ${ }^{[3,4]}$. Drug-induced apoptosis is readily characterized by microvilli, cell shrinkage, chromatin condensation, nuclear collapse and cellular fragmentation into apoptotic-bodies. The anticancer activity of current anticancer drugs is mediated by multiple apoptotic mechanisms, for example, the activation of mitogenactivated protein (MAP) kinases and caspases. The MAP kinases ERK, p38, and JNK are involved in the regulation of cell proliferation, differentiation and cell death ${ }^{[5,6]}$. ERK

\footnotetext{
* To whom correspondence should be addressed.

E-mail jrong@hkucc.hku.hk

Received 2013-08-13 Accepted 2013-09-29
}

isoenzymes are mainly regulated by the ras/raf/MEK pathway but are also activated by MEK-1-dependent signals ${ }^{[7-9]}$. Activation of ERKs promotes the proliferation and survival of most cell types ${ }^{[7,10]}$ and regulates cell differentiation and apoptosis ${ }^{[11,12]}$. In contrast, the MAP kinases JNK and p38 are often activated by oxidative stress and xenobiotics, and they subsequently induce apoptosis and promote the production of pro-inflammatory cytokines ${ }^{[7,13]}$. Interestingly, JNK and p38 exist in multiple isoforms and function in a cell-type-specific manner ${ }^{[14]}$. Moreover, their individual isoenzymes may reside in different intracellular compartments and regulate different biological events ${ }^{[15,16]}$. Under certain circumstances, p38 and JNK could exert opposing functions and even attenuate cellular apoptotic signals ${ }^{[17]}$. Nevertheless, recent studies suggest that p38 and/or JNK directly activate the caspase cascade, thereby mediating the activation of the apoptotic transcription factor c-jun ${ }^{[18,19]}$. Activation of the caspase cascade actu- 
ally hallmarks cell apoptosis ${ }^{[20]}$, and notably, many anticancer drugs kill tumor cells by mainly activating caspases, especially caspase- $-3^{[3,21,22]}$.

Bornyl caffeate was initially isolated as an anti-inflammatory and antibacterial compound from several plants, such as Piper caninum (Piperaceae), Piper philippinum, Coreopsis mutica var mutica and Verbesina turbacenina Kunth ${ }^{[23-26]}$. Recent studies have further demonstrated that bornyl caffeate inhibits human neutrophil elastase, HIV-1 integrase and trypanosome cysteine protease ${ }^{[26-28]}$. The chemical structure of bornyl caffeate represents a combination of two naturally occurring, anti-inflammatory compounds, namely, borneol and caffeic acid. Borneol is widely used to treat against microorganisms, inflammation and pain in Traditional Chinese medicine and other folk medicines ${ }^{[29,30]}$. However, borneol could be cytotoxic and genotoxic, depending on its concentration ${ }^{[30,31]}$. At non-toxic concentrations, borneol attenuates the cytotoxicity and genotoxicity of hydrogen peroxide $\left(\mathrm{H}_{2} \mathrm{O}_{2}\right)$, whereas borneol at higher concentrations manifests synergy with $\mathrm{H}_{2} \mathrm{O}_{2}$, primarily by potentiating the DNA-damaging effects of $\mathrm{H}_{2} \mathrm{O}_{2}$. Interestingly, borneol and its derivative MT103 inhibited 7, 12-dimethylbenz(a)anthracene-induced carcinogenesis and tumor growth, while both compounds barely showed toxicity in normal cells ${ }^{[32,33]}$. It is believed that borneol kills cancer cells largely by inducing apoptosis. However, caffeic acid and its derivatives are known for their antioxidant, anti-inflammatory and antiviral activities ${ }^{[2,34-38]}$. For example, caffeic acid phenethyl ester (CAPE) from insect propolis specifically induces apoptosis in tumor or virally transformed cells but not in parental, normal cells ${ }^{[39,40]}$. Octylcaffeate, another example, was recently synthesized and evaluated for its antioxidant, anti-inflammatory and anticancer activities ${ }^{[35,41,42]}$. Octylcaffeate also induces apoptosis in human cancer cells and prevents experimental lung metastasis of murine colon 26-L5 carcinoma cells $^{[43,44]}$.

The present study was designed to explore the anticancer potential of bornyl caffeate. We recently synthesized bornyl caffeate via direct esterification of caffeic acid with borneol and found that bornyl caffeate strongly induced cell death in human breast cancer MCF-7 cells. The research focus of the present study was to understand the molecular mechanism underlying the cytotoxicity of bornyl caffeate in breast cancer MCF-7 cells.

\section{Materials and methods}

\section{Chemicals and antibodies}

The antibodies against phospho-Akt, phospho-ERK, phosphop38, phospho-JNK, Akt, ERK, p38, and JNK were purchased from Cell Signaling Technology (Boston, MA, USA). The antibodies against Bax, Bcl-2, Bcl-xl, caspase-3, PARP were purchased from Santa Cruz Biotechnology (Santa Cruz, CA, USA). The antibody against GAPDH and the goat anti-rabbit IgG horseradish peroxidase (HRP) conjugate antibody were purchased from Sigma-Aldrich Co (St Louis, MO, USA). Other chemicals were obtained from Sigma-Aldrich Co (St Louis, MO, USA) unless indicated otherwise.
Bornyl caffeate was synthesized from caffeic acid by exhaustive esterification with borneol following a modified procedure that was described previously ${ }^{[45]}$. At the end of reaction, bornyl caffeate was purified by silica gel chromatography and characterized by nuclear magnetic resonance (NMR) spectroscopy and mass spectrometry (MS). In this study, bornyl caffeate was diluted in dimethylsulfoxide (DMSO) to make stock solutions of $1 \mathrm{mmol} / \mathrm{L}$ and was filtrated using a sterile filter (Millipore, USA). For cell culture, bornyl caffeate was diluted to the appropriate final concentrations in cell-culture medium. Control cells were treated with the same amount of vehicle. The DMSO concentration in the cell-culture medium was controlled below $0.1 \%(v / v)$.

\section{Cell culture}

MCF-7 and several other cell lines (T47D, HepG2, HeLa and PC12) were obtained from the American Type Cell Culture Collection (Manassas, VA, USA). MCF-7, T47D, HepG2, and HeLa cells were maintained in Dulbecco's modified Eagle's medium (DMEM) supplemented with 10\% fetal bovine serum (FBS) (Invitrogen, USA) and 1\% penicillin/streptomycin (Invitrogen, USA). PC12 cells were maintained in Dulbecco's modified Eagle's medium (DMEM) supplemented with 10\% fetal bovine serum (FBS) (Invitrogen, USA), 5\% horse serum (Invitrogen, USA) and 1\% penicillin/streptomycin (Invitrogen, USA). All cells were cultured at $37^{\circ} \mathrm{C}$ in a humidified, $5 \% \mathrm{CO}_{2}$ atmosphere.

\section{Measurement of cell viability}

The cell viability was evaluated by a standard colorimetric assay as described previously ${ }^{[46]}$. In brief, the cells were seeded at $1 \times 10^{4} / 100 \mu \mathrm{L}$ per well in a 96-well plate and treated with $0,10,25$, and $50 \mu \mathrm{mol} / \mathrm{L}$ of bornyl caffeate for $24 \mathrm{~h}$ or 50 $\mu \mathrm{mol} / \mathrm{L}$ of bornyl caffeate for $0,3,6,12$, and $24 \mathrm{~h}$. At the end of the drug treatment, the cell monolayers were incubated with 3-[4,5-dimethylthiazol-2-yl]-2,5-diphenyltetrazolium bromide (MTT) solution $(0.5 \mathrm{mg} / \mathrm{mL})$ in phosphate-buffered saline (PBS) for $4 \mathrm{~h}$. The formation of purple formazan was quantified by measuring the absorbance at $570 \mathrm{~nm}$ on a microplate reader (Bio-Rad, USA). To characterize the cytotoxicity of bornyl caffeate, MCF-7 cells were pretreated with $20 \mu \mathrm{mol} / \mathrm{L}$ of different protein kinase inhibitors (LY294002, PD98059, SP600125, and SB203580) or $50 \mu \mathrm{mol} / \mathrm{L}$ of z-VADfmk for $1 \mathrm{~h}$ and then treated with bornyl caffeate at the indicated concentrations for $24 \mathrm{~h}$. The cell viability was determined using the MTT assay as described above.

\section{Measurement of lactate dehydrogenase (LDH) release}

Extracellular LDH activity was measured using a colorimetric assay and the Cytotoxicity Cell Death Kit (Sigma, USA) according to the manufacturer's instructions. Briefly, MCF-7 cells were seeded in 96-well culture plates at a density of 10000 cells per well. Bornyl caffeate at various final concentrations $(0,10,25$, and $50 \mu \mathrm{mol} / \mathrm{L})$ or $50 \mu \mathrm{mol} / \mathrm{L}$ of bornyl caffeate was added for the indicated times, and the supernatants were collected to assay LDH activity. The absorbances of 
all samples were measured at $490 \mathrm{~nm}$ on a microplate reader (Bio-Rad, USA).

\section{Morphological changes in MCF-7 cells}

Cells were washed twice with PBS and then stained with 5 $\mu \mathrm{mol} / \mathrm{L}$ Hoechst 33342 in $1 \times$ PBS solution for $10 \mathrm{~min}$ at room temperature. The cell morphology was examined using a Zeiss fluorescence microscope (Carl Zeiss, Germany), and the apoptotic cells were defined by chromatin condensation and fragmentation of nuclei.

\section{Flow cytometric analysis of apoptotic cells}

After the treatment with bornyl caffeate, the cells $\left(1 \times 10^{6}\right)$ were freshly harvested and suspended in a 1:1 $(v / v)$ mixture of PBS and $0.2 \mathrm{~mol} / \mathrm{L} \mathrm{Na}_{2} \mathrm{HPO}_{4}-0.1 \mathrm{~mol} / \mathrm{L}$ citric acid ( $\left.\mathrm{pH} 7.5\right)$. Following fixation with ice-cold ethanol at $4{ }^{\circ} \mathrm{C}$ for $1 \mathrm{~h}$, the cells were resuspended in Annexin $\mathrm{V}$ binding buffer and then incubated in a buffer containing $200 \mathrm{ng} / \mathrm{mL}$ Annexin V-FITC conjugates at room temperature for $15 \mathrm{~min}$. Subsequently, the cells were stained with PI ( $300 \mathrm{ng} / \mathrm{mL})$ for $10 \mathrm{~min}$, and the stained cells were analyzed on a FACSCalibur flow cytometer (BD Biosciences, San Jose, CA, USA).

\section{ROS Determination}

The intracellular ROS level was measured based on the ROS-induced formation of the highly fluorescent product $2^{\prime}, 7^{\prime}$-dichlorofluorescein (DCF) from the non-fluorescent dye $2^{\prime}, 7^{\prime}$-dichlorofluorescin diacetate (DCFH-DA), as previously described $^{[47,48]}$. Briefly, MCF-7 cells were seeded in a 6-well plate at a density of $2 \times 10^{5}$ cells per well and incubated for $24 \mathrm{~h}$ at $37^{\circ} \mathrm{C}$. Following treatment with bornyl caffeate $(0,10,25$, or $50 \mu \mathrm{mol} / \mathrm{L})$, the cells were loaded with $20 \mu \mathrm{mol} / \mathrm{L} 2^{\prime}, 7^{\prime}$-dichlorofluorescin diacetate (DCFH-DA) in serum-free DMEM medium for $30 \mathrm{~min}$ at $37^{\circ} \mathrm{C}$. After the removal of excessive DCFH-DA, the cells were analyzed on a FACSCalibur flow cytometer (BD Biosciences, USA).

\section{Visualization of mitochondrial membrane potential}

The mitochondrial membrane potential (MMP) was assessed using 5,5',6,6' -tetrachloro-1,1',3,3'-tetraethyl-benzimidazolcarbocyanine iodide (JC-1) (Invitrogen, USA) as previously described $^{[49]}$. The cells were cultured in 24-well plates. After a 24-h treatment with bornyl caffeate, the cells were incubated for $30 \mathrm{~min}$ at $37^{\circ} \mathrm{C}$ with $1 \mu \mathrm{g} / \mathrm{mL}$ of JC-1 in growth medium. MMP depolarization was visualized by measuring fluorescence at the emission wavelengths of $530 \mathrm{~nm}$ and $590 \mathrm{~nm}$ after excitement at a wavelength of $485 \mathrm{~nm}$ with a Zeiss fluorescence microscope (Carl Zeiss, Germany).

\section{Western blotting analysis}

The cellular proteins were extracted and analyzed for protein expression as previously described ${ }^{[47,50]}$. Briefly, $30 \mu \mathrm{g}$ of cellular proteins were resolved by electrophoresis in a $10 \%$ SDS-polyacrylamide gel and subsequently transferred to polyvinylidene difluoride (PVDF) membrane. Following a 1-h incubation in fresh TBS buffer containing 0.1\% Tween-20 and
$5 \%$ skimmed milk powder, the blots were probed with specific antibodies including rabbit anti-Akt, anti-ERK, anti-p38, antiJNK, anti-caspase-3, anti-PARP, anti-Bax, anti-Bcl-2, antiBcl-xl, anti-GAPDH, anti-phospho-Akt, anti-phospho-ERK, anti-phospho-p38, anti-phospho-JNK, or anti-cleaved PARP. The bound primary antibodies were detected using a goat anti-rabbit IgG-HRP conjugate. The activity of peroxidase on the blot was visualized by enhanced chemiluminescence (ECL) detection reagents (GE Healthcare, Sweden). To characterize the effects of the antioxidants on the bornyl caffeate-induced activation of MAP kinases, MCF-7 cells were pretreated with $1 \mathrm{mmol} / \mathrm{L}$ of different antioxidants, except for vitamin C (100 $\mu \mathrm{mol} / \mathrm{L})$, for $1 \mathrm{~h}$, and this was followed by treatment with bornyl caffeate $(50 \mu \mathrm{mol} / \mathrm{L})$ for $24 \mathrm{~h}$. The intracellular proteins were extracted and analyzed by Western blot analysis using specific antibodies.

\section{Statistical analysis}

The data are presented as the means \pm SD for three independent experiments. Statistical analysis was performed using a twotailed, paired Student's $t$-test, and a $P$-value $<0.05$ was considered to be statistically significant.

\section{Results}

\section{Synthesis and cytotoxicity of bornyl caffeate}

Bornyl caffeate was recently synthesized by exhaustive esterification of caffeic acid with borneol as described (Figure 1) ${ }^{[45]}$. The cytotoxicity of bornyl caffeate was evaluated by the standard colorimetric MTT assay in MCF-7 cells, which served as a cell model of human breast cancer ${ }^{[46]}$. Following the exposure to bornyl caffeate at concentrations of $0,10,25$, and 50 $\mu \mathrm{mol} / \mathrm{L}$ for $24 \mathrm{~h}$ or at a concentration of $50 \mu \mathrm{mol} / \mathrm{L}$ for $0,3,6$, 12 , and $24 \mathrm{~h}$, cell viability was assayed based on the reduction of MTT by mitochondrial reductase in viable cells. As shown in Figure 2A and 2B, bornyl caffeate reduced the cell viability in a concentration- and time-dependent manner. In similar experiments, caffeic acid and borneol showed no cytotoxicity at a concentration of $50 \mu \mathrm{mol} / \mathrm{L}$ after $24 \mathrm{~h}$ (data not shown). Bornyl caffeate was also found to be cytotoxic in other cancer cells such as HepG2, Hela, T47D, and PC12 (data not shown). The cytotoxicity of bornyl caffeate was also verified by measuring LDH release. As shown in Figure 2C and 2D, the LDH activity in the medium was increased in a concentration- and time-dependent manner. Typically, bornyl caffeate at a con-

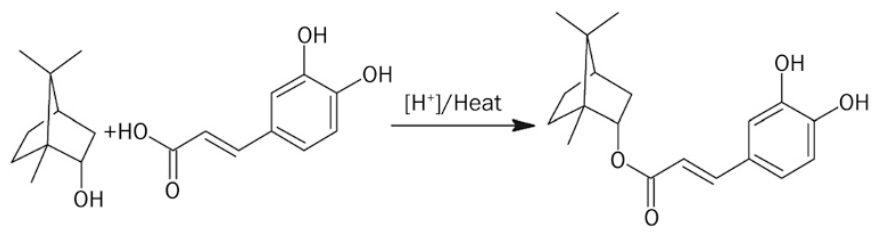

Figure 1. Scheme illustrating the chemical synthesis of bornyl caffeate. Bornyl caffeate was synthesized via acid-catalyzed esterification of caffeic acid with borneol. The structures were generated using the chemistry software ACD/ChemSketch (http://www.acdlabs.com). 

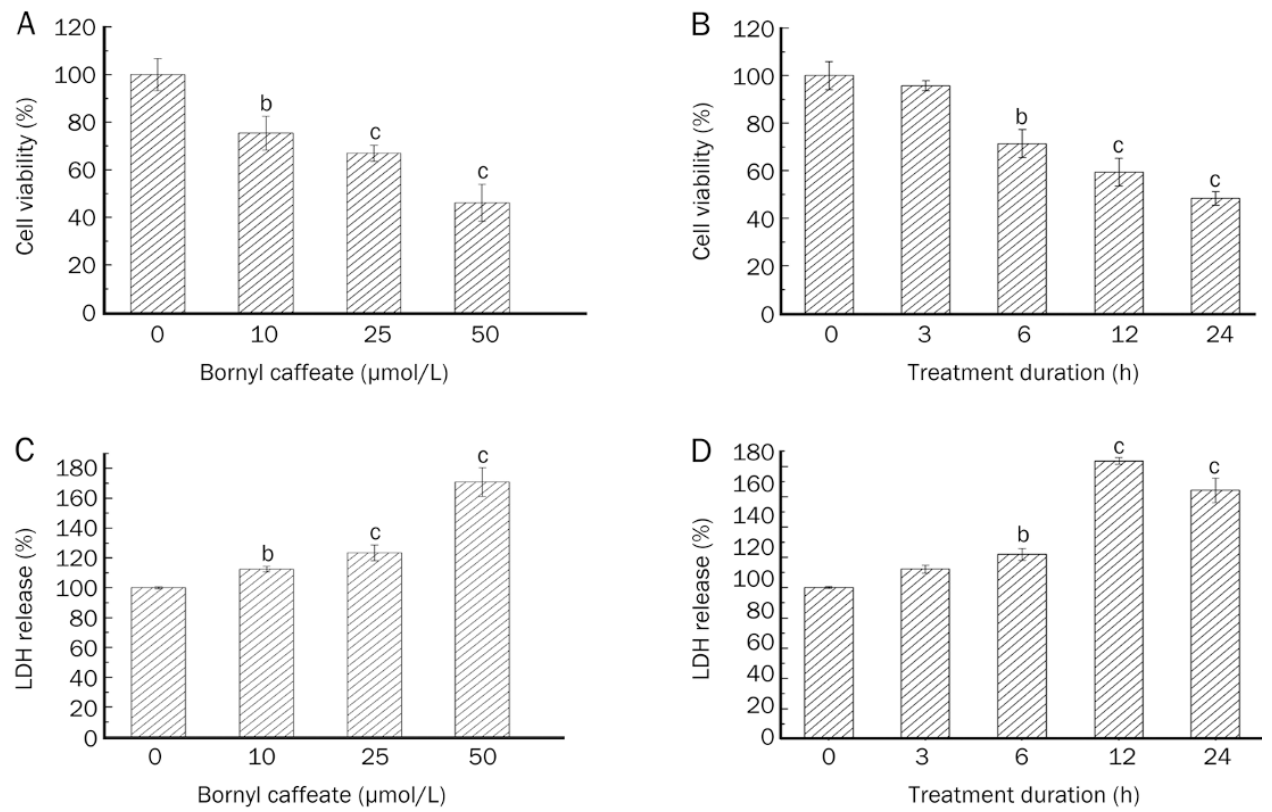

Figure 2. Effect of bornyl caffeate on the cell viability of human breast cancer MCF-7 cells. (A) Dose-dependence of cytotoxicity. The cells were treated for $24 \mathrm{~h}$ with bornyl caffeate at the indicated doses. (B) Time-dependence of cytotoxicity. The cells were treated with $50 \mu \mathrm{mol} / \mathrm{L}$ of bornyl caffeate at each time point, whereas the control cells were treated with DMSO. At the end of drug treatment, the cell viability was determined using the MTT assay. The results are expressed as a percentage of the corresponding control. (C) Dose-dependence of LDH release. The cells were treated for $24 \mathrm{~h}$ with bornyl caffeate at the indicated doses. (D) Time-dependence of LDH release. The cells were treated with $50 \mu \mathrm{mol} / \mathrm{L}$ of bornyl caffeate at each time point, whereas the control cells were treated with DMSO. At the end of drug treatment, the cell viability was determined using the MTT assay, and the results are expressed as a percentage of the corresponding control. The mean, SEM, was usually within $10 \%$ of the mean value $(n=3)$. $\left({ }^{b} P<0.05\right.$, ${ }^{\mathrm{c}} P<0.01$ vs control).

centration of $50 \mu \mathrm{mol} / \mathrm{L}$ significantly induced the release of the LDH enzyme after a 6-h incubation. These results suggest that bornyl caffeate may be a potential cytotoxic reagent for cancer cells.

\section{Bornyl caffeate induced apoptosis in human breast cancer MCF-} 7 cells

To characterize the cytotoxicity of bornyl caffeate, we treated MCF-7 cells with the compound at concentrations of $0,10,25$, and $50 \mu \mathrm{mol} / \mathrm{L}$ for $24 \mathrm{~h}$. We first examined the nuclear morphology of MCF-7 cells by staining with Hoechst 33342. Upon exposure to bornyl caffeate, the incorporation of fluorescent dye was increased in a concentration-dependent manner (Figure $3 \mathrm{~A}$ ), and it was clear that bornyl caffeate induced the formation of condensed and fragmented cell nuclei (see arrows). Secondly, we detected the appearance of the early apoptosis biomarker phospho-serine at the cell surface by Annexin V-FITC staining. As shown in Figure 3B, bornyl caffeate increased the number of Annexin V-FITC-positive cells in a concentration-dependent manner. Due to the loss of cellmembrane integrity, the incorporation of the fluorescent dye PI was similarly increased. Thirdly, we investigated the effect of bornyl caffeate on the mitochondrial membrane potential (MMP) using a cationic fluorescent probe JC-1. JC-1 is preferably incorporated into the mitochondrion of viable cells, giving rise to a maximal fluorescence emission at $\sim 590 \mathrm{~nm}$ (red), whereas the maximal fluorescence emission of JC-1 in the cytosol appears at $\sim 525 \mathrm{~nm}$ (green). By measuring such a shift in the fluorescence emission by fluorescence microscopy, mitochondrial polarization was readily detected in bornyl caffeatetreated cells (Figure 3C). Notably, in the cells exposed to 50 $\mu \mathrm{M}$ of bornyl caffeate, a significant amount of the fluorescent dye JC-1 was present in the cytosol rather than the mitochondria (see arrows).

\section{Bornyl caffeate stimulates ROS formation}

To clarify the effect of bornyl caffeate on the intracellular redox status, we determined the intracellular ROS level by measuring the oxidation of non-fluorescent DCFH-DA to its highly fluorescent derivative 2 ', $7^{\prime}$-dichlorofluorescein (DCF). As shown in Figure 3D, bornyl caffeate stimulated ROS formation in a concentration-dependent manner.

\section{Effect of bornyl caffeate on apoptosis biomarkers}

To verify the induction of apoptosis by bornyl caffeate, we investigated the effect of bornyl caffeate on the expression of the pro-apoptotic protein Bax and anti-apoptotic proteins Bcl-2 and Bcl-xl. We found that bornyl caffeate up-regulated the intracellular level of Bax but down-regulated the intracellular level of Bcl-xl in a concentration-dependent manner (Figure 4A and $4 \mathrm{~B}$ ). The expression of Bcl-2 was not dramatically affected even when the drug concentration was increased as high as 50 $\mu \mathrm{mol} / \mathrm{L}$. We further clarified if bornyl caffeate could trigger the activation of the caspase cascade by monitoring the cleav- 
Treatment with bornyl caffeate $(\mu \mathrm{mol} / \mathrm{L})$
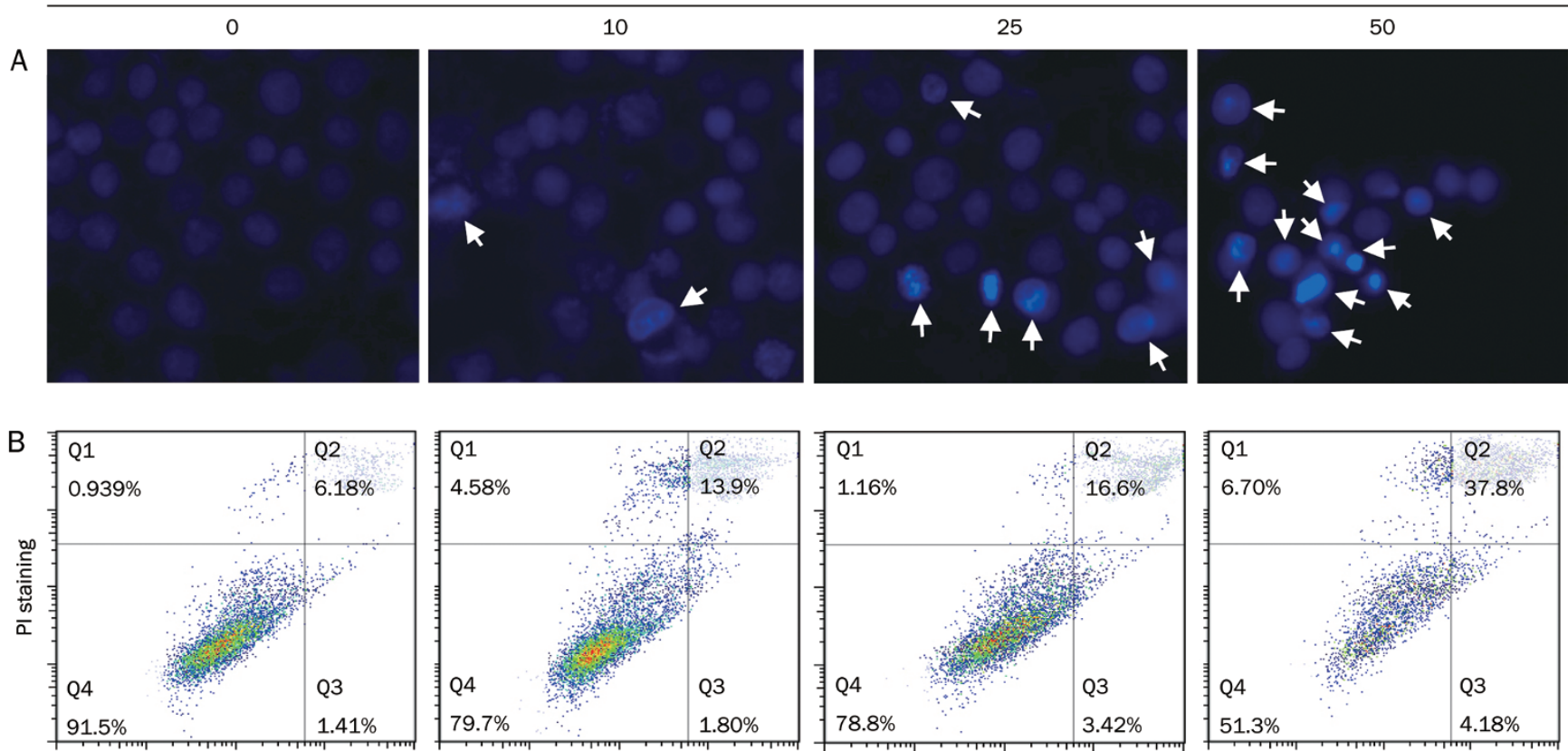

Annexin V-FITC staining
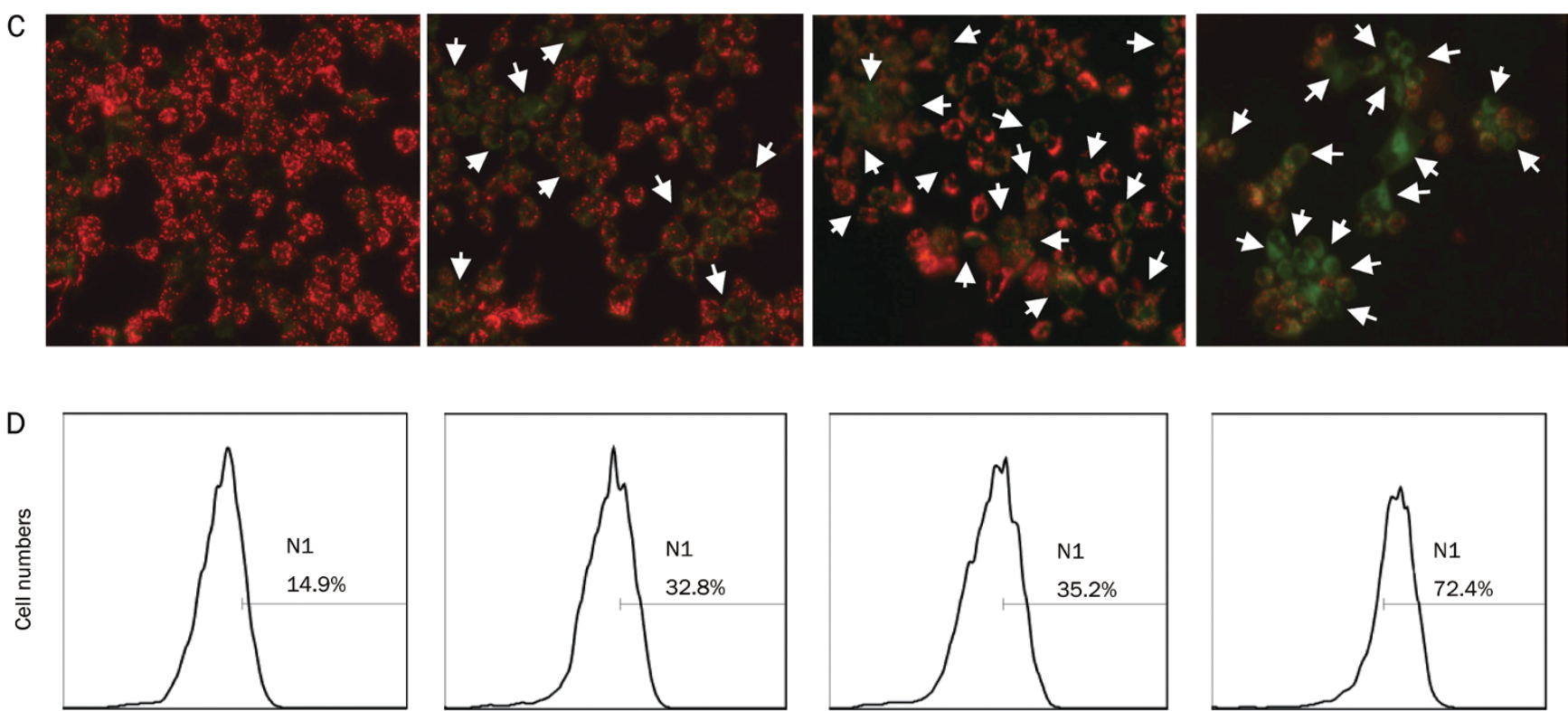

Fluorescence intensity

Figure 3. Bornyl caffeate induces apoptosis in human breast cancer MCF-7 cells. (A) Effect of bornyl caffeate on the morphology of cell nuclei. MCF7 cells were treated with $0,10,25$, or $50 \mu \mathrm{mol} / \mathrm{L}$ of bornyl caffeate for $24 \mathrm{~h}$ and subsequently stained with Hoechst 33258 , and the images were captured by fluorescence microscopy. The arrows point to the condensed and/or fragmented cell nuclei. (B) Flow cytometric analysis of the cell-surface phosphoserine. MCF-7 cells were sequentially treated with $0,10,25$, or $50 \mu \mathrm{mol} / \mathrm{L}$ bornyl caffeate for $24 \mathrm{hr}$, co-stained with Annexin V-FITC and PI and analyzed by flow cytometry (FACSCalibur, BD Biosciences, USA). (C) Effect of bornyl caffeate on the mitochondrial membrane potential. Cells were treated with $0,10,25$, or $50 \mu \mathrm{mol} / \mathrm{L}$ of bornyl caffeate for $24 \mathrm{~h}$ and subsequently stained with a fluorescent dye DJ-1. The cells were visualized for their green and red emission components by using optical filters designed for fluorescein and tetramethylrhodamine fluorescence microscopy. The arrows point to the cells undergoing depolarization of the mitochondrial membrane. (D) Effect of bornyl caffeate on the formation of ROS. Cells were treated with $0,10,25$, and $50 \mu \mathrm{mol} / \mathrm{L}$ of bornyl caffeate for $24 \mathrm{~h}$. The ROS levels were determined by assaying the fluorescent product $2^{\prime}, 7^{\prime}$-dichlorofluorescein (DCF) from 2',7'-dichlorofluorescin diacetate (DCFH-DA) in viable cells on a flow cytometer (FACSCalibur, BD Biosciences, USA).

age of caspase-3 and its action on PARP. As shown in Figure $4 \mathrm{C}$ and $4 \mathrm{D}$, bornyl caffeate at concentrations of 10,25 , and
$50 \mu \mathrm{mol} / \mathrm{L}$ triggered the cleavage of caspase-3. Importantly, upon activation, caspase-3 subsequently degraded PARP, 
A

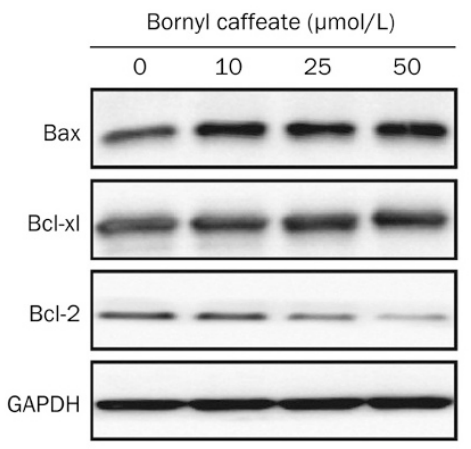

C

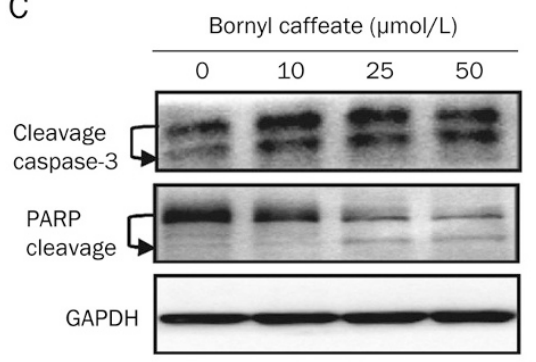

B
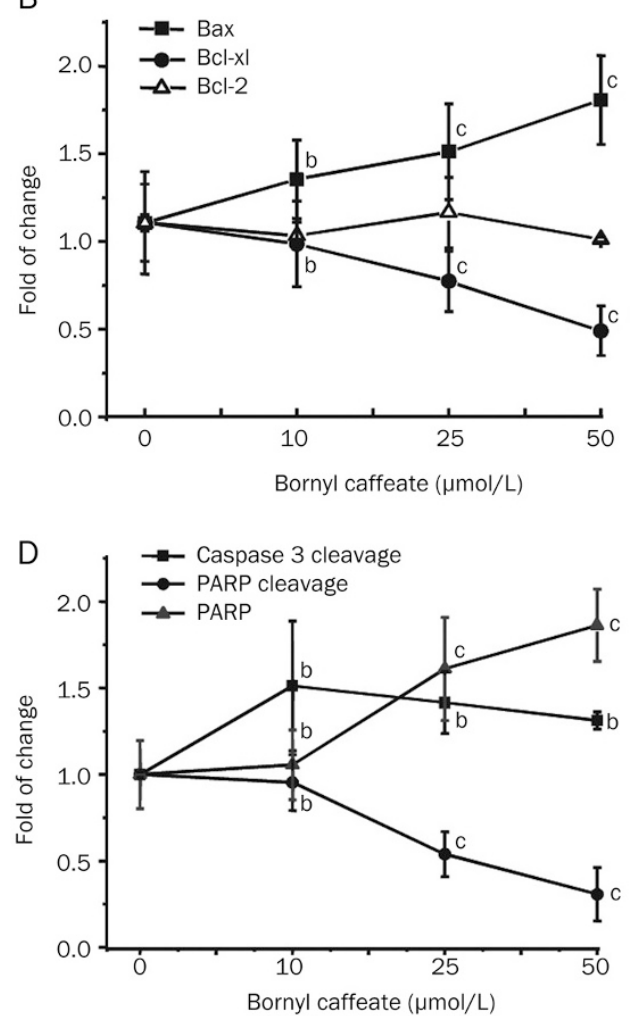

Figure 4. Effect of bornyl caffeate on the expression and bioprocessing of apoptosis-related biomarkers. (A) Western blot analysis of Bax, Bcl-2, and BclXL. MCF-7 cells were treated with bornyl caffeate at concentrations of $0,10,25$, or $50 \mu \mathrm{mol} / \mathrm{L}$ for $24 \mathrm{~h}$. Bax, Bcl-xl, and Bcl-2 were detected by specific antibodies, whereas GAPDH was detected as the internal control. (B) Data quantification of Panel A. The Western blots were quantified and expressed as the fold change of signal intensity compared to the untreated sample after normalization to the corresponding GAPDH signals. (C) Western blot analysis of caspase-3 and PARP cleavage. At the end of treatment, the cellular proteins were analyzed for caspase-3 and PARP cleavage by specific antibodies in the same way as described in Panel A. (D) Data quantification of Panel C. The data were analyzed in the same way as described in Panel B, and the results were presented as the means \pm SD of three independent experiments $\left({ }^{b} P<0.05,{ }^{c} P<0.01\right.$ vs control).

giving rise to a reduction in the intracellular PARP level in a concentration-dependent manner.

\section{Bornyl caffeate persistently activates the MAP kinases JNK and p38}

To explore the mechanisms modulating the induction of apoptosis, we investigated the effect of bornyl caffeate on different protein kinases. MCF-7 cells were treated with bornyl caffeate $(50 \mu \mathrm{mol} / \mathrm{L})$ for various periods $(0,0.5,1,3,6$, and $12 \mathrm{~h})$. At the end of treatment, the cellular proteins were resolved by $10 \%$ SDS-PAGE and analyzed by Western blotting. As shown in Figure 5A and 5B, two pro-survival kinases, Akt and ERK, were marginally activated at the early stage (0.5-3 h); however, the phospho-Akt and phospho-ERK signals were gradually reduced to basal levels. In contrast, the phosphop38 and phospho-JNK signals were gradually increased over a period of $12 \mathrm{~h}$. These results stimulated us to further examine if activation of the MAP kinases p38 and JNK was dependent on the concentration of bornyl caffeate. We found that bornyl caffeate at a concentration of $50 \mu \mathrm{mol} / \mathrm{L}$ induced a dramatic increase in the phospho-p38 and phospho-JNK signals, whereas, at concentrations of 10 and $25 \mu \mathrm{mol} / \mathrm{L}$, the phospho- p38 and phospho-JNK signals were barely detectable (data not shown).

Antioxidants differentially attenuate the activation of the MAP kinases p38 and JNK

To understand how bornyl caffeate activated the MAP kinases p38 and JNK, we focused on the potential role of intracellular ROS. We employed four common antioxidants, NAC, GSH, vitamin $\mathrm{C}$, and Trolox, to scavenge intracellular ROS. By detecting phospho-p38 and phospho-JNK in cells that were treated with bornyl caffeate and antioxidants, alone or in combination, we found that antioxidants differentially affected the activation of p38 and JNK by bornyl caffeate. In particular, antioxidants effectively antagonized the effect of bornyl caffeate on the activation of p38 but showed little activity against the activation of JNK (Figure $5 \mathrm{C}$ ).

\section{Characterization of the cytotoxicity of bornyl caffeate}

To explore the mechanisms by which bornyl caffeate induced apoptosis, we first investigated the effect of protein kinase inhibitors on the cytotoxicity of bornyl caffeate. As shown in Figure 6A, the p38 inhibitor SB203580 and JNK inhibitor 
A

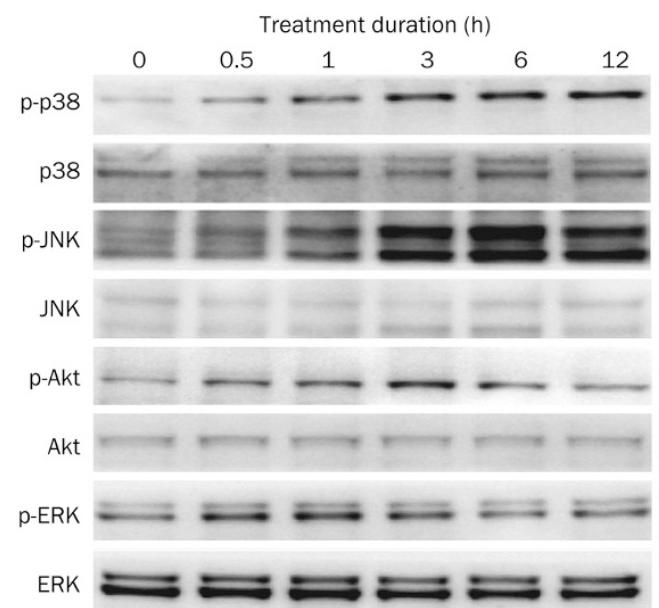

B

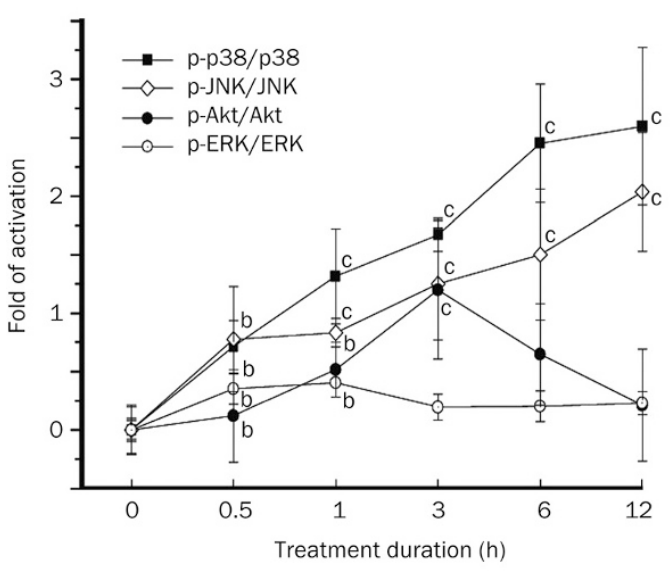

C

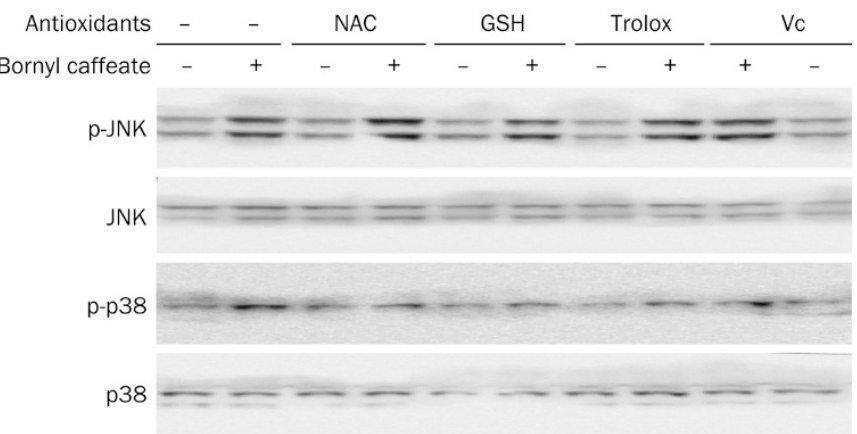

Figure 5. Bornyl caffeate differentially activated MAP kinases in MCF7 cells. (A) Effect of bornyl caffeate on MAP kinases. MCF-7 cells were treated with $50 \mu \mathrm{mol} / \mathrm{L}$ bornyl caffeate for the indicated times. Total cell lysates were extracted, resolved by 10\% SDS-PAGE and transferred onto PVDF membrane. The phosphorylated and total proteins of Akt, ERKs, p38 MAPK, and JNKs were immunodetected. (B) Quantification of Panel A. The Western blots were quantified and expressed as the fold change of the signal intensity value compared to the untreated sample after normalization to the corresponding GAPDH signals. The results are presented as the means \pm SD of three independent experiments, $\left({ }^{\mathrm{b}} P<0.05\right.$, ${ }^{\mathrm{c}} P<0.01$ vs control). (C) Effects of antioxidants on the bornyl caffeateinduced activation of MAP kinases. MCF-7 cells were pretreated with 1 $\mathrm{mmol} / \mathrm{L}$ of different antioxidants, except for vitamin C $(100 \mu \mathrm{mol} / \mathrm{L})$, for $1 \mathrm{~h}$ followed by treatment with $50 \mu \mathrm{mol} / \mathrm{L}$ bornyl caffeate for $24 \mathrm{~h}$. The intracellular proteins were extracted and analyzed by Western blot using specific antibodies.
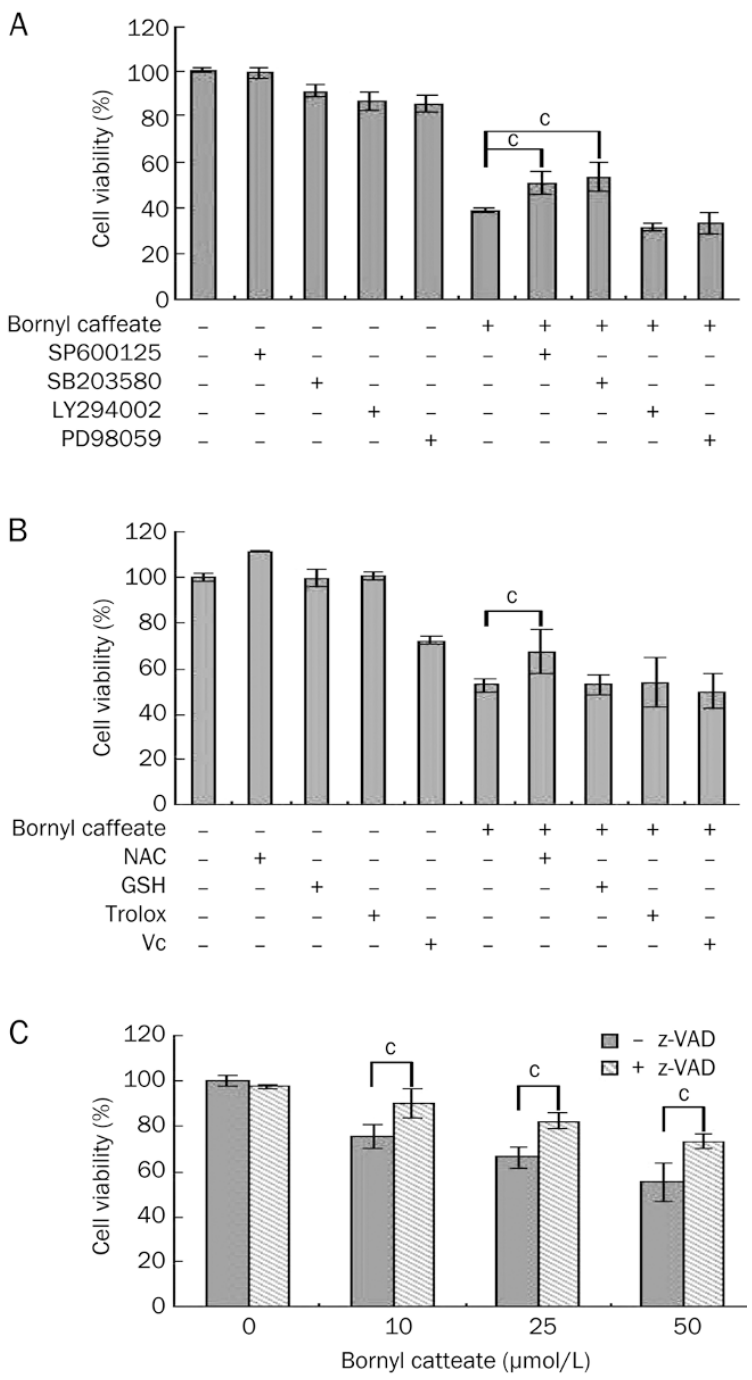

Figure 6. Investigation of potential mechanisms underlying the cytotoxicity of bornyl caffeate. (A) Effect of protein kinase inhibitors on the cytotoxicity of bornyl caffeate. MCF-7 cells were pretreated with different protein kinase inhibitors (PI3 kinase inhibitor LY294002, ERK inhibitor PD98059, p38 MAP kinase inhibitor SP600125 or JNK inhibitor SB203580) for $1 \mathrm{~h}$ followed by treatment with $50 \mu \mathrm{mol} / \mathrm{L}$ bornyl caffeate for $24 \mathrm{~h}$. Cell viability was determined using the standard MTT assay. (B) Effect of different antioxidants on the cytotoxicity of bornyl caffeate. MCF7 cells were pretreated with $1 \mathrm{mmol} / \mathrm{L}$ of different antioxidants, except for vitamin C (100 $\mu \mathrm{mol} / \mathrm{L})$, for $1 \mathrm{~h}$ followed by treatment with $50 \mu \mathrm{mol} / \mathrm{L}$ bornyl caffeate for $24 \mathrm{~h}$. The cell viability was determined using the standard MTT assay. (C) Effect of the pan-caspase inhibitor z-VAD-fmk on the cytotoxicity of bornyl caffeate. MCF-7 cells were pretreated with $50 \mu \mathrm{mol} / \mathrm{L} z$-VAD-fmk for $1 \mathrm{~h}$ followed by treatment with $50 \mu \mathrm{mol} / \mathrm{L}$ bornyl caffeate for $24 \mathrm{~h}$. The cell viability was determined using the standard MTT assay $\left({ }^{b} P<0.05,{ }^{c} P<0.01\right.$ vs control).

SP600125 significantly attenuated the cytotoxicity of bornyl caffeate, whereas neither the ERK inhibitor PD98059 nor the PI3K/Akt inhibitor LY294002 showed any effect. These results suggest that activation of the MAP kinases p38 and JNK plays a role in the cytotoxicity of bornyl caffeate (Martin et al, 2004). 
Second, we investigated the effect of different antioxidants on the cytotoxicity of bornyl caffeate. To our surprise, all of these antioxidants, except for the thiol antioxidant L-NAC, failed to protect the cells against the cytotoxicity of bornyl caffeate (Figure 6). Third, we investigated the effect of the pan-caspase inhibitor z-VAD on the cytotoxicity of bornyl caffeate. As shown in Figure 6C, inhibition of caspases by z-VAD resulted in partial protection of the cells against the cytotoxicity of bornyl caffeate. Taken together, the cytotoxicity of bornyl caffeate can be partially attenuated by scavenging ROS and inhibiting MAP kinases and the caspase cascade.

\section{Discussion}

In the present study, we investigated the anticancer mechanisms of bornyl caffeate in the human breast cancer cell line MCF-7. By assaying the effect of bornyl caffeate on the reduction of MTT in viable cells and the release of lactate dehydrogenase (LDH) from dead cells, we found that bornyl caffeate exhibited strong cytotoxicity in breast cancer MCF-7 cells in a dose- and time-dependent manner (Figure 2). To explore the underlying mechanisms for this process, we further characterized the cytotoxicity of bornyl caffeate by examining the morphological changes of cell nuclei and the presentation of the early apoptotic marker phosphoserine at the cell surface. As shown in Figure 3A and 3B, bornyl caffeate increased the shrinkage of cell nuclei and staining of Annexin V-FITC in a concentration-dependent manner, suggesting an apoptotic mechanism. These apoptotic features were supported by an increase in the protein level of pro-apoptotic Bax and a decrease in the intracellular level of anti-apoptotic Bcl-xl (Figure 4A). In line with the increase in the expression of the mitochondria-damaging protein Bax, bornyl caffeate actually disrupted the integrity of the mitochondrial membrane and induced the activation of caspase- 3 (Figure $3 \mathrm{C}$ and $4 \mathrm{C}$ ). These results stimulate us to postulate that the cytotoxicity of bornyl caffeate is mediated by inducing apoptosis in cancer cells.

Induction of apoptosis is a major anticancer mechanism for a variety of cancer therapies ${ }^{[3]}$. Caffeate derivatives such as CAPE and octylcaffeate have been previously demonstrated to induce apoptosis in various cancer cell lines and animal mod$\mathrm{els}^{[43,51]}$. The common caffeate group in these compounds is presumably the key structural element responsible for inducing apoptosis. Bornyl caffeate is a combination of two wellknown, anti-inflammatory chemical elements, caffeate and borneol, which renders this compound a potential anticancer drug candidate. Our results provided experimental evidence that support the potential of bornyl caffeate in inducing apoptosis in the breast cancer cell line MCF-7. We also observed similar cytotoxicity in several other cancer cell lines such as hepatoma HepG2, cervical cancer HeLa and pheochromocytoma PC12 cells (data not shown). Drug-induced apoptosis of cancer cells is ultimately executed by the caspase cascade, especially through caspase $3 / 6 / 7^{[52,53]}$. However, various anticancer drugs, irradiation and Fas ligand may induce apoptosis through different mechanisms ${ }^{[4,54]}$.

Aberrant formation of ROS is well recognized as a carcino- genic factor driving the malignant transformation of normal cells via inducing oxidative DNA damage ${ }^{[5,56]}$. However, the induction of ROS formation plays an important role in the chemotherapeutic activity of several anticancer drugs and a large number of anticancer compounds ${ }^{[57,58]}$. Drug-induced ROS mediates the activation of MAP kinases, disrupts MMP and ultimately activates apoptotic caspases in cancer cells ${ }^{[59-61]}$. Following treatment with bornyl caffeate, the intracellular ROS levels were measured using a widely used, permeable probe $2^{\prime}, 7^{\prime}$-dichlorofluorescin diacetate (DCFH-DA) ${ }^{[62]}$. After passive loading to the cells, DCFH-DA is hydrolyzed into $2^{\prime}, 7^{\prime}$-dichlorodihydrofluorescin (DCFH) by intracellular esterase. DCFH is subsequently oxidized by ROS to become the highly fluorescent compound $2^{\prime}, 7^{\prime}$-dichlorofluorescein (DCF). As shown in Figure 3D, bornyl caffeate stimulated ROS formation in a concentration-dependent manner. To determine the effect of bornyl caffeate on the integrity of the mitochondrial membrane, we selected a cationic dye, JC-1, to indicate mitochondrial polarization. Previous studies suggest that JC-1 forms red-fluorescent J-aggregates more specifically in the mitochondria and offers better consistency in its response to drug-induced depolarization than other cationic dyes such as DiOC6(3) and rhodamine $123^{[63]}$. We separately visualized the green and red emission components by using optical filters designed for fluorescein and tetramethylrhodamine. As a result, we observed that bornyl caffeate caused mitochondrial depolarization in a concentration-dependent manner (Figure 3C). Moreover, bornyl caffeate profoundly upregulated the Bax level and downregulated the Bcl-xL level, thereby causing a dramatic shift in the Bax/Bcl-xL ratio to allow mitochondrial apoptosis to occur ${ }^{[64]}$. As shown in Figure 4C, apoptosisexecuting molecules such as caspase- 3 and its substrate poly (ADP-ribose) polymerase (PARP) were sequentially activated. Interestingly, pre-treatment with the pan-caspase inhibitor z-VAD-fmk only partially inhibited bornyl caffeate-induced apoptosis, suggesting the involvement of caspase-dependent and -independent mechanisms $s^{[65,66]}$.

ROS regulates cell proliferation, differentiation and apoptosis via the activation of protein kinase C (PKC), ERK, the p38 MAP kinase and $\mathrm{JNK}^{[19,67,68]}$. In cells exposed to $50-\mu \mathrm{mol} / \mathrm{L}$ bornyl caffeate, we detected a gradual increase in phospho-p38 and phospho-JNK MAP kinases over a period of $12 \mathrm{~h}$, whereas phospho-Akt and phospho-ERK1/2 were only detectable during the first $3 \mathrm{hrs}$ (Figure 5A). To determine the mechanism by which bornyl caffeate acts on the p38 MAP kinase and JNK, we applied different antioxidants to scavenger the ROS that were induced by bornyl caffeate. The antioxidants NAC, GSH, Trolox, and vitamin C attenuated the activation of the p38 MAP kinase by bornyl caffeate but showed little effect on the activation of JNK (Figure 5C). These results suggest that bornyl caffeate could induce the activation of the MAP kinases p38 and JNK via ROSdependent and -independent pathways. Not surprisingly, JNK can be activated by multiple stimuli such as cytokines (eg, tumor necrosis factor and interleukin-1), reactive oxygen species (ROS), pathogens, toxins, drugs, endoplasmic reticulum 
stress, free fatty acids and metabolic changes ${ }^{[69]}$. For example, garlic-derived, organosulfur compounds such as diallyl polysulfides activate JNK via direct chemical modification of the cytoskeletal protein tubulin and depends less on intracellular $\operatorname{ROS}^{[70]}$. Another study demonstrated that the proinflammatory mediator high-mobility group box-1 protein (HMGB1) induced MUC8 expression in a JNK and PI3K/ Akt signaling pathway-dependent manner that was ROSindependent ${ }^{[71]}$. Further investigation is needed to clarify how bornyl caffeate activates JNK in a ROS-independent manner. To explore the mechanisms underlying the cytotoxicity of bornyl caffeate, we employed antioxidants, the JNK inhibitor SP600125, the p38 MAP kinase inhibitor SB203850, the PI3K/ Akt inhibitor LY294002 and the pan-caspase inhibitor z-VADfmk. As shown in Figure 6, the cytotoxicity of bornyl caffeate was partially attenuated by the JNK inhibitor SP600125, p38 MAP kinase inhibitor SB203850 and antioxidants NAC and pan-caspase $z-V A D-f m k$. However, none of these reagents could completely rescue the cells from bornyl caffeate-induced injury. These results suggest that the cytotoxicity of bornyl caffeate is mediated by multiple mechanisms.

In conclusion, the present study demonstrated that bornyl caffeate induced cell death in breast cancer MCF-7 cells by inducing apoptosis. We found that bornyl caffeate stimulated the formation of ROS and activated the stress-responsive MAP kinases JNK and p38 in MCF-7 cells. Our results suggest that ROS-dependent pathways and the ROS-independent JNK pathway contribute to the cytotoxicity of bornyl caffeate. Thus, bornyl caffeate may serve as a potential lead for the development of new anticancer drugs.

\section{Acknowledgements}

This work was supported by the Seed Funding Programme for Basic Research, University of Hong Kong (Project 201111159212, to JR) and the National Natural Science Foundation of China, Specialized Research Fund for the Doctoral Program of Higher Education on 2011 (project 20106101110001, to $\mathrm{XZ)}$.

\section{Author contribution}

Chuan-bin YANG, Jia ZHAO, and Yuan-yuan CHENG performed the research; Wei-jing PEI and Xiao-hui ZHENG chemically synthesized bornyl caffeate; Jian-hui RONG designed the research and analyzed the data; and Jian-hui RONG and Chuan-bin YANG wrote the paper.

\section{References}

1 Hetts SW. To die or not to die. JAMA: the journal of the American Medical Association 1998; 279: 300-7.

2 Zhou Y, ZHANG Wp. Caffeic acid ameliorates early and delayed brain injuries after focal cerebral ischemia in rats1. Acta pharmacologica sinica 2006; 27: 1103-10.

3 Bamford M, Walkinshaw G, Brown R. Therapeutic applications of apoptosis research. Experimental cell research 2000; 256: 1.

4 Kaufmann SH, Earnshaw WC. Induction of apoptosis by cancer chemotherapy. Experimental cell research 2000; 256: 42.

5 Johnson GL, Lapadat R. Mitogen-activated protein kinase pathways mediated by ERK, JNK, and p38 protein kinases. Science Signalling 2002; 298: 1911.

6 Wada T, Penninger JM. Mitogen-activated protein kinases in apoptosis regulation. Oncogene 2004; 23: 2838-49.

7 Lewis TS, Shapiro PS, Ahn NG. Signal transduction through MAP kinase cascades. Advances in cancer research 1998; 74: 49-139.

8 Band CJ, Posner Bl. Phosphatidylinositol 3'-kinase and p70s6k are required for insulin but not bisperoxovanadium 1,10-phenanthroline [bpV (phen)] inhibition of insulin-like growth factor binding protein gene expression. Journal of Biological Chemistry 1997; 272: 138-45.

9 Grammer TC, Blenis J. Evidence for MEK-independent pathways regulating the prolonged activation of the ERK-MAP kinases. Oncogene 1997; 14: 1635-42.

10 Wang X, Martindale JL, Liu Y, Holbrook NJ. The cellular response to oxidative stress: influences of mitogen-activated protein kinase signalling pathways on cell survival. Biochem J 1998; 333 (Pt 2): 291-300.

11 Traverse S, Gomez N, Paterson H, Marshall C, Cohen P. Sustained activation of the mitogen-activated protein (MAP) kinase cascade may be required for differentiation of PC12 cells. Comparison of the effects of nerve growth factor and epidermal growth factor. Biochemical Journal 1992; 288 (Pt 2): 351.

12 Ishikawa Y, Kitamura M. Dual potential of extracellular signalregulated kinase for the control of cell survival. Biochemical and biophysical research communications 1999; 264: 696-701.

13 Obata T, Brown GE, Yaffe MB. MAP kinase pathways activated by stress: the p38 MAPK pathway. Critical care medicine 2000; 28: N67-N77.

14 Kang KW, Ryu JH, Kim SG. The essential role of phosphatidylinositol 3-kinase and of p38 mitogen-activated protein kinase activation in the antioxidant response element-mediated rGSTA2 induction by decreased glutathione in H4IIE hepatoma cells. Mol Pharmacol 2000; 58: 1017-25.

15 Gupta S, Barrett T, Whitmarsh AJ, Cavanagh J, Sluss HK, Derijard $B$, et al. Selective interaction of JNK protein kinase isoforms with transcription factors. The EMBO Journal 1996; 15: 2760.

16 Jiang Y, Gram H, Zhao M, New L, Gu J, Feng L, et al. Characterization of the structure and function of the fourth member of p38 group mitogen-activated protein kinases, p38delta. J Biol Chem 1997; 272: 30122-8.

17 Minamino T, Yujiri T, Papst PJ, Chan ED, Johnson GL, Terada N. MEKK1 suppresses oxidative stress-induced apoptosis of embryonic stem cell-derived cardiac myocytes. Proc Natl Acad Sci U S A 1999; 96: 15127-32.

18 Harada J, Sugimoto M. Activation of caspase-3 in $\beta$-amyloid-induced apoptosis of cultured rat cortical neurons. Brain research 1999; 842: 311-23.

19 Davis RJ. Signal transduction by the JNK group of MAP kinases. Cell 2000; 103: 239-52.

20 Budihardjo I, Oliver H, Lutter M, Luo X, Wang X. Biochemical pathways of caspase activation during apoptosis. Annual review of cell and developmental biology 1999; 15: 269-90.

21 Borner C, Monney L. Apoptosis without caspases: an inefficient molecular guillotine? Cell death and differentiation 1999; 6: 497.

22 Leist M, Jaattela M. Four deaths and a funeral: from caspases to alternative mechanisms. Nature Reviews Molecular Cell Biology 2001; 2: 589-98.

23 Maldonado E, Ramírez Apan M, Perez-Castorena AL. Antiinflammatory activity of phenyl propanoids from Coreopsis mutica var. mutica. Planta medica 1998; 64: 660-61.

24 Setzer WN, Setzer MC, Bates RB, Nakkiew P, Jackes BR, Chen L, et 
al. Antibacterial hydroxycinnamic esters from Piper caninum from Paluma, north Queensland, Australia. The crystal and molecular structure of (+)-bornyl coumarate. Planta medica 1999; 65: 747.

25 Chen YC, Liao $\mathrm{CH}$, Chen IS. Lignans, an amide and anti-platelet activities from Piper philippinum. Phytochemistry 2007; 68: 210111.

26 Ogungbe IV, Crouch RA, Haber WA, Setzer WN. Phytochemical investigation of verbesina turbacensis kunth: trypanosome cysteine protease inhibition by (-)-bornyl esters. Natural Product Communications 2010; 5: 1161-66.

27 Steinbrecher T, David A, Labahn A. A multistep approach to structurebased drug design: Studying ligand binding at the human neutrophil elastase. Journal of medicinal chemistry 2006; 49: 1837-44.

28 Xia C, Li H, Hu W. Synthesis of trans-caffeate analogues and their bioactivities against HIV-1 integrase and cancer cell lines. Bioorganic \& medicinal chemistry letters 2008; 18: 6553-57.

29 Cha JD, Jeong MR, Jeong SI, Lee KY. Antibacterial activity of sophoraflavanone $\mathrm{G}$ isolated from the roots of Sophora flavescens. Journal of microbiology and biotechnology 2007; 17: 858.

30 Mulyaningsih S, Youns M, El-Readi MZ, Ashour ML, Nibret E, Sporer F, et al. Biological activity of the essential oil of Kadsura longipedunculata (Schisandraceae) and its major components. Journal of Pharmacy and Pharmacology 2010; 62: 1037-44.

31 Slamenova D, Horvathova E, Wsolova L, Sramkova M, Navarova J. Investigation of anti-oxidative, cytotoxic, DNA-damaging and DNAprotective effects of plant volatiles eugenol and borneol in humanderived HepG2, Caco-2 and VH10 cell lines. Mutat Res 2009; 677: 46-52.

$32 \mathrm{Kim} \mathrm{Y,} \mathrm{Cerbo} \mathrm{R,} \mathrm{Hah} \mathrm{C,} \mathrm{Bahn} \mathrm{K,} \mathrm{Kim} \mathrm{J,} \mathrm{Ha} \mathrm{Y.} \mathrm{Growth} \mathrm{inhibition} \mathrm{of}$ osteosarcoma cell MG-63 by a mixture of trans, trans conjugated linoleic acid isomers: possible mechanistic actions. Journal of food science 2008; 73: T7-T15.

33 Jasinski P, Zwolak P, Isaksson Vogel R, Bodempudi V, Terai K, Galvez $\mathrm{J}$, et al. MT103 inhibits tumor growth with minimal toxicity in murine model of lung carcinoma via induction of apoptosis. Investigational new drugs 2011; 29: 846-52.

34 Fesen MR, Pommier Y, Leteurtre F, Hiroguchi S, Yung J, Kohn KW. Inhibition of HIV-1 integrase by flavones, caffeic acid phenethyl ester (CAPE) and related compounds. Biochemical pharmacology 1994; 48: 595-608.

35 Hsiao G, Shen MY, Lin KH, Lan MH, Wu LY, Chou DS, et al. Antioxidative and hepatoprotective effects of Antrodia camphorata extract. Journal of Agricultural and Food Chemistry 2003; 51: 3302-8.

36 Orban Z, Mitsiades N, Burke Jr TR, Tsokos M, Chrousos GP. Caffeic acid phenethyl ester induces leukocyte apoptosis, modulates nuclear factor-kappa B and suppresses acute inflammation. Neuroimmunomodulation 2000; 7: 99-105.

37 Kwon KH, Barve A, Yu S, HUANG MT, KONG ANT. Cancer chemoprevention by phytochemicals: potential molecular targets, biomarkers and animal models1. Acta Pharmacologica Sinica 2007; 28: 140921.

38 Zhang L, Ji Z. Synthesis, antiinflammatory and anticancer activity of cinnamic acids, their derivatives and analogues. Acta Pharmaceutica Sinica 1992; 27: 823-23.

39 Su Z, Lin J, Grunberger D, Fisher PB. Growth suppression and toxicity induced by caffeic acid phenethyl ester (CAPE) in type 5 adenovirustransformed rat embryo cells correlate directly with transformation progression. Cancer research 1994; 54: 1865-70.

40 Chen JH, Shao Y, Huang MT, Chin CK, Ho CT. Inhibitory effect of caffeic acid phenethyl ester on human leukemia HL-60 cells. Cancer letters 1996; 108: 211-14.
41 Fiuza S, Gomes C, Teixeira L, Girão da Cruz M, Cordeiro M, Milhazes N, et al. Phenolic acid derivatives with potential anticancer properties a structure-activity relationship study. Part 1: Methyl, propyl and octyl esters of caffeic and gallic acids. Bioorganic \& medicinal chemistry 2004; 12: 3581-89.

42 da Cunha FM, Duma D, Assreuy J, Buzzi FC, Niero R, Campos MM, et al. Caffeic acid derivatives: in vitro and in vivo anti-inflammatory properties. Free radical research 2004; 38: 1241-53.

43 Ujibe M, Kanno S, Osanai Y, Koiwai K, Ohtake T, Kimura K, et al. Octylcaffeate induced apoptosis in human leukemia U937 cells. Biological and Pharmaceutical Bulletin 2005; 28: 2338-41.

44 Nagaoka T, Banskota AH, Tezuka Y, Harimaya Y, Koizumi K, Saiki I, et al. Inhibitory effects of caffeic acid phenethyl ester analogues on experimental lung metastasis of murine colon 26-L5 carcinoma cells. Biological and Pharmaceutical Bulletin 2003; 26: 638-41.

45 Etzenhouser B, Hansch C, Kapur S, Selassie CD. Mechanism of toxicity of esters of caffeic and dihydrocaffeic acids. Bioorganic \& medicinal chemistry 2001; 9: 199-209.

46 Rong J, Tilton R, Shen J, Ng KM, Liu C, Tam PKH, et al. Genome-wide biological response fingerprinting (BioReF) of the Chinese botanical formulation ISF-1 enables the selection of multiple marker genes as a potential metric for quality control. Journal of ethnopharmacology 2007; 113: 35-44.

47 Qi H, Siu So, Chen Y, Han Y, Chu IK, Tong Y, et al. Senkyunolides reduce hydrogen peroxide-induced oxidative damage in human liver HepG2 cells via induction of heme oxygenase-1. Chemico-biological interactions 2010; 183: 380-89.

48 Qi H, Chen B, Le XC, Rong J. Concomitant induction of heme Oxygenase-1 attenuates the cytotoxicity of arsenic species from lumbricus extract in human liver HepG2 cells. Chemistry \& Biodiversity 2012; 9: 739-54.

49 Choi IY, Lee SJ, Ju C, Nam W, Kim HC, Ko KH, et al. Protection by a manganese porphyrin of endogenous peroxynitrite-induced death of glial cells via inhibition of mitochondrial transmembrane potential decrease. Glia 2000; 31: 155-64.

50 Rong J, Cheung C, Lau A, Shen J, Tam P, Cheng YC. Induction of heme oxygenase-1 by traditional Chinese medicine formulation ISF-1 and its ingredients as a cytoprotective mechanism against oxidative stress. International journal of molecular medicine 2008; 21: 405.

51 Chen YJ, Shiao MS, Hsu ML, Tsai TH, Wang SY. Effect of caffeic acid phenethyl ester, an antioxidant from propolis, on inducing apoptosis in human leukemic HL-60 cells. Journal of agricultural and food chemistry 2001; 49: 5615-19.

52 Sanmartín C, Plano D, Sharma AK, Palop JA. Selenium compounds, apoptosis and other types of cell death: an overview for cancer therapy. International Journal of Molecular Sciences 2012; 13: 9649-72.

53 Thornberry NA, Lazebnik Y. Caspases: enemies within. Science 1998; 281: 1312-6.

54 Strand S, Hofmann WJ, Hug H, Müller M, Otto G, Strand D, et al. Lymphocyte apoptosis induced by CD95 (APO-1/Fas) ligandexpressing tumor cells - A mechanism of immune evasion? Nature medicine 1996; 2: 1361-66.

55 Lee JC, Son YO, Pratheeshkumar P, Shi X. Oxidative stress and metal carcinogenesis. Free Radical Biology and Medicine 2012.

56 Klaunig JE, Kamendulis LM, Hocevar BA. Oxidative stress and oxidative damage in carcinogenesis. Toxicologic pathology 2010; 38: 96-109.

57 Fruehauf JP, Meyskens FL. Reactive oxygen species: a breath of life or death? Clinical Cancer Research 2007; 13: 789-94.

58 Trachootham D, Alexandre J, Huang P. Targeting cancer cells by ROS- 
mediated mechanisms: a radical therapeutic approach? Nature Reviews Drug Discovery 2009; 8: 579-91.

59 Benhar M, Engelberg D, Levitzki A. ROS, stress-activated kinases and stress signaling in cancer. EMBO reports 2002; 3: 420-25.

60 Zhang L, Yu J, Park BH, Kinzler KW, Vogelstein B. Role of BAX in the apoptotic response to anticancer agents. Science Signalling 2000; 290: 989.

61 Raza H, John A, Benedict S. Acetylsalicylic acid-induced oxidative stress, cell cycle arrest, apoptosis and mitochondrial dysfunction in human hepatoma HepG2 cells. European journal of pharmacology 2011; 668: 15-24.

62 Eruslanov E, Kusmartsev S. Identification of ROS using oxidized DCFDA and flow-cytometry. Methods Mol Biol 2010; 594: 57-72.

63 Mason W. Fluorescent and luminescent probes for biological activity: a practical guide to technology for quantitative real-time analysis. Second Edition ed. London, UK Academic Press; 1999.

64 Rohlena J, Dong LF, Ralph SJ, Neuzil J. Anticancer drugs targeting the mitochondrial electron transport chain. Antioxidants \& redox signaling 2011; 15: 2951-74.

65 Yim D, Singh RP, Agarwal C, Lee S, Chi H, Agarwal R. A novel anticancer agent, decursin, induces G1 arrest and apoptosis in human prostate carcinoma cells. Cancer research 2005; 65: 1035-
44.

66 Liu H, Liu Y, Liu Y, Xu A, Young CYF, Yuan H, et al. A novel anticancer agent, retigeric acid $\mathrm{B}$, displays proliferation inhibition, $\mathrm{S}$ phase arrest and apoptosis activation in human prostate cancer cells. Chemicobiological interactions 2010; 188: 598-606.

67 Chang L, Karin M. Mammalian MAP kinase signalling cascades. Nature 2001; 410: 37-40.

68 Kyriakis JM, Avruch J. Mammalian mitogen-activated protein kinase signal transduction pathways activated by stress and inflammation. Physiol Rev 2001; 81: 807-69.

69 Seki E, Brenner DA, Karin M. A liver full of JNK: signaling in regulation of cell function and disease pathogenesis, and clinical approaches. Gastroenterology 2012.

70 Kelkel M, Cerella C, Mack F, Schneider T, Jacob C, Schumacher M, et al. ROS-independent JNK activation and multisite phosphorylation of $\mathrm{Bcl}-2$ link diallyl tetrasulfide-induced mitotic arrest to apoptosis. Carcinogenesis 2012.

71 Kim DE, Min K, Kim JS, Kwon TK. High-mobility group box-1 protein induces mucin 8 expression through the activation of the JNK and $\mathrm{PI} 3 \mathrm{~K} /$ Akt signal pathways in human airway epithelial cells. Biochemical and Biophysical Research Communications 2012. 